\title{
Hydrography of the Mouth of the English Channel, 1925-1928.
}

\author{
By \\ H. W. Harvey, M.A., \\ Hydrographer at the Plymouth Laboratory.
}

With 16 Figures in the Text.

THE temperature of the sea and the movements of water carrying with it planktonic organisms have been the subject of study since the early days of marine biological research. As investigation of cold-blooded marine animals progresses, the controlling rôle played by the temperature of the surrounding water upon their breeding, rate of growth, and general metabolism, becomes increasingly evident.

From 1902 to 1909 cruises were made throughout the English Channel by the s.s. Huxley four times each year, and from the data so obtained Matthews (1905-11) described the distribution of temperature at these times, as well as the distribution of salinity, and from these the general water movements were deduced. Conditions at the same time of year differed from one year to another. It was concluded that fluctuations from year to year in the annual temperature cycle and fluctuations in the inflow of water from the Atlantic would have a profound influence upon the population of marine animals and upon the fisheries. This conclusion has been borne out in this area notably by the researches of Orton (1920) upon the narrow temperature limits in which various marine animals breed, and of Ford (1929) upon the shoaling of herring for breeding purposes.

Since 1921 more frequent but less extensive cruises have been made by the s.s. Salpa, while surface temperature samples have been collected at intervals of about two weeks by cross-Channel steamers (see Fig. 1) for the Ministry of Agriculture and Fisheries, with the exception of the route Land's End to Ushant, on which data are collected for the Marine Biological Association. These surface data are published in the annual Bulletin Hydrographique of the International Council for the Exploration of the Sea. Hydrographic cruises have also been made to the west and south-west of the entrance to the Channel by French and Irish fishery research vessels, the data being published in the Rapport Atlantique. These data so collected throw light upon the fluctuations which have 
occurred from year to year in both the movement of the water masses and in the annual cycle of temperature.

\section{PART I. TEMPERATURE DISTRIBUTION.}

\section{The Annual Cycle.}

The annual variation, or temperature cycle, differs from place to place and from time to time with the extent to which the surface layers mix with the water below, and with the depth or mass of water which is heated in summer and is cooled in winter. Further, the cycle fluctuates from year to year owing to fluctuating meteorological conditions, and on occasions owing to the inflow of water from other parts.

In shallow areas, where wave motion and turbulence due to tidal streams keep the upper layers mixed with the water below and in consequence keep the temperature nearly constant from top to bottom, the water commences to rise in temperature about a month before the vernal equinox and attains a maximum in the late summer. Such is found, for instance, in Plymouth Sound and in the shallow eastern part of the English Channel.

In the deeper waters of the Channel it is otherwise.

There is now a considerable body of data concerning the temperature cycle at Station $\mathrm{E}_{1}\left(50^{\circ} 02^{\prime}\right.$ N., $4^{\circ} 22^{\prime}$ W. $)$ in a depth of around 71 metres. Here convection currents, wave motion, and vertical mixing set up by tidal streaming are effective in keeping the temperature almost the same from top to bottom during the winter. Later, as the water warms, receiving heat from solar radiation at the surface, there comes a time in May, June or July when heat arrives more rapidly at a depth of about 16 to 20 metres than the turbulent eddy motion of the water can carry it to greater depths. The resulting difference in density, between this upper warmed layer or epithalassa and the water below, still further damps down eddy motion at the discontinuity layer. Heat can only pass slowly through it to the water below. From this discontinuity layer to the bottom the water remains more or less isothermal, because tidal streaming over the bottom sets up eddy motion which is sufficient to pass downwards the heat which is arriving from the epithalassa.

Figure 2 shows the distribution of temperature which had been attained on August 2nd and 3rd, 1927, at Stations $\mathrm{E}_{1}$ and $\mathrm{E}_{3}, 74$ and 106 metres deep respectively.

Between 15 and 20 metres there is a sharp change in density, and in consequence considerable work must be done if the lighter water above is to mix with the heavier water below (Atkins, 1925). Vertical movement of water particles is tolerably free to take place between the surface and 10 or 15 metres. Hence heat from solar radiation, which is absorbed near 
the surface, is freely passed on downwards from water particle to water particle to this depth by the eddying movements of the particles themselves, brought about by wave motion and the convection currents set up by cooling at night. If it were not for this mixing of the water particles carrying heat just as they carry momentum, and passing it on as in a relay race in the course of their eddy movements, the layering would be much shallower and higher temperatures would be attained near the surface, as happens in still water.

In the discontinuity layer the interchange or mixing of the water particles and their eddy movements are restrained. Hence momentum is not freely passed downwards, and this upper stratum is relatively free to slip horizontally over the heavier water, the slip taking place at the discontinuity layer. This undoubtedly takes place. At Station $\mathrm{E}_{1}$ the water swings to and fro up and down Channel with the tides from the surface to near the bottom; it appears that it does not swing to and fro as a whole body, but at times the upper stratum is travelling faster and slipping over the heavier water. A series of observations indicated also that the discontinuity layer oscillates vertically up and down to a slight extent.

Although the upper stratum is distinct, the many series of observations made at $\mathrm{E}_{1}$ do not show sharp differences in salinity between this epithalassa and the heavier water; there is no reason to suppose that the warm upper stratum flows in from other areas to cover the cooler water, yet summer land drainage doubtless flows out freely to mix with the upper stratum rather than diluting the deeper water. When an inflow of water into the $\mathrm{E}_{1}$ area occurs during the summer, it is sometimes the case that high salinity water creeps in along the bottom.

Usually some time in August, as the intensity of solar radiation wanes, there is a gradual cooling of the upper warm layer, heat being lost from the surface by evaporation, by radiation outwards, particularly at night, and by gradual passage through the discontinuity layer into the cooler water below. Convection currents set up by loss of heat from the surface penetrate deeper and deeper, until finally the layering breaks down, often hastened by a gale, and isothermal conditions result.

At this time, usually in September or October, the deep water attains its maximum temperature (Fig. 3) unless, as happened in 1921, a mass of warmer water flows in from a neighbouring area.

During October and November the loss of heat from the mixed water is rapid. An analysis of factors leads to the inference that evaporation from the surface plays a major part in regulating the rate of cooling. During these two months in particular the vapour pressure of the relatively warm surface water exceeds the pressure of aqueous vapour in the 
atmosphere (Harvey, 1925). By February or the beginning of March the minimum temperature is reached and the annual cycle completed.

While the formation of an upper warm layer is taking place in the open sea, every variant up to isothermal distribution with depth occurs as the shore or shallow areas are approached. Observations made on the line between Station $\mathrm{E}_{1}$ and Plymouth on August 7th, 1924, reproduced in Figure 4 show this very clearly.

The water in Plymouth Sound is in connection with the large body of water in the Channel which tends to stabilise its temperature. On plotting the temperatures observed near the western end of Plymouth Breakwater, they are seen to be a little lower during the height of summer than the surface temperatures at $\mathrm{E}_{1}$, vertical mixing being more active, and distinctly lower than the temperatures at the Varne Light vessel in the Straits of Dover, the centre of an extensive area under 40 metres in depth.

During the winter, inshore and shallower water temperatures are lower than in deep areas, similar heat losses having greater effect on shallower depths. The observations on January 7th, 1929, shown in Figure 4, illustrate this, as also the crosses in Figure 3. At the Varne Light vessel the winter temperatures are still lower. It is a fair generalisation that the annual range of temperature is greater the shallower the water and the less interchange taking place with the deeper open sea.

\section{Surface Temperatures.}

The surface temperature of the sea is usually taken from a sample drawn in a bucket and is usually taken as representative of the upper 4 to 6 inches. On a cloudy day or with a strong breeze there is rarely any distinct difference from the temperature at 5 metres, but with a clear sky during the afternoon in summer or after a frosty night in winter with a smooth sea the difference may be material, although unusual in this area. The matter is of some importance since a very great quantity of surface temperature data have been accumulated for the English Channel and North Sea, and from these charts can be drawn for the whole body of water during the winter months when isothermal conditions are known to exist. During the summer months the temperature of the upper 5 metres is so dependent upon vertical mixing due to wind, that such charts would have restricted value, except in the shallower areas, such as the eastern part of the English Channel, where vertical mixing overcomes the tendency towards layering. In view of this Table I has been compiled in order to give an idea of the source of error likely to arise in using surface temperature data. All the observations were made at about midday, while if they 
had been made in the early morning doubtless some of the differences might have been greater; on the other hand, they were made on days when the sea was slight or moderate, while if the sea had been moderate or rough the differences would have been less.

\section{TABLE I}

\begin{tabular}{|c|c|c|c|c|c|c|}
\hline 1921 & $\begin{array}{l}\text { October. } \\
\left\{\begin{array}{l}+0 \cdot 04^{\circ} \mathrm{C} . \\
+0 \cdot 12\end{array}\right.\end{array}$ & $\begin{array}{l}\text { November. } \\
-0.70^{\circ} \\
-0.04\end{array}$ & $\begin{array}{l}\text { December. } \\
-0 \cdot 19^{\circ}\end{array}$ & January. & February. & March. \\
\hline 1922 & $+0 \cdot 10$ & +0.01 & & -0.06 & $-0 \cdot 61$ & $-0 \cdot 04$ \\
\hline 1923 & +0.02 & $-0 \cdot 18$ & $-0 \cdot 35$ & $\left.\begin{array}{l}-0.05 \\
-0.35\end{array}\right\}$ & $-0 \cdot 11$ & +0.08 \\
\hline 1924 & -0.02 & $-0 \cdot 39$ & $-0 \cdot 03$ & -0.06 & $-0 \cdot 25$ & \\
\hline 1925 & $+0 \cdot 40$ & & $-0 \cdot 03$ & +0.01 & $-0 \cdot 19$ & +0.06 \\
\hline 1926 & -0.09 & -0.05 & $\left.\begin{array}{r}0.00 \\
+0.08\end{array}\right\}$ & & $-0 \cdot 10$ & $+0 \cdot 10$ \\
\hline 1927 & $+0 \cdot 10$ & +0.25 & $+0 \cdot 12$ & & +0.02 & +0.30 \\
\hline 1928 & $+0 \cdot 01$ & $0 \cdot 00$ & & $+0 \cdot 12$ & $+0 \cdot 17$ & $-0 \cdot 02$ \\
\hline 1929 & $-0 \cdot 10$ & & & $\left.\begin{array}{l}-\cdot 02 \\
-\cdot 15\end{array}\right\}$ & $\left.\begin{array}{l}+.05 \\
+\cdot 30\end{array}\right\}$ & 0.00 \\
\hline
\end{tabular}

\section{Fludotuations in the Annual Cycle.}

Not only does the maximum temperature attained at the end of summer, and the minimum temperature to which the water falls at the end of winter fluctuate from year to year, but the dates at which some particular temperature is attained differ greatly. It is perhaps the latter which is most significant to the biologist, since the breeding of many marine animals is strictly limited to a relatively narrow range of temperature. As a case in point the water near the bottom at $\mathrm{E}_{1}$ rose to $12^{\circ} \mathrm{C}$. at about the third week in June in 1921, and at the end of first week in August in 1924 , and to $13^{\circ} \mathrm{C}$. at about mid-July in 1921, and during the third week in September in 1924. It is obvious that such a fluctuation would have a profound effect upon any animal which breeds in the region of $12^{\circ}-13^{\circ} \mathrm{C}$.

The interval of about a month between each set of observations does not allow a precise value being given for the maximum and minimum temperatures attained each year by the surface water at Station $\mathrm{E}_{1}$, but tolerably approximate values can be taken from faired curves for these temperatures and the dates they were attained in deeper water. These are shown in Table II. 


\section{TABLE II.}

Approximate Maximum and Minimum Temperatures Attained by the Lower Stratum of Water at Station $\mathrm{E}_{1}$, and Dates at WHICH SUCH WERE ATTAINED.

\begin{tabular}{lll} 
Year. & \multicolumn{1}{c}{ Maximum temperatures. } & Minimum temperatures. \\
1921 & $15 \cdot 4^{\circ} \mathrm{C}$. third week in October & - \\
1922 & $14 \cdot 2$ end September & $9 \cdot 5$ early April \\
1923 & $13 \cdot 5$ first week in October & $9 \cdot 2$ March \\
1924 & $13 \cdot 1$ early October & $7 \cdot 9$ March \\
1925 & $13 \cdot 6$ end first week in October & $9 \cdot 1$ late March \\
1926 & $14 \cdot 5$ third week in October & $9 \cdot 3$ March \\
1927 & $13 \cdot 7$ early October & $9 \cdot 0$ late March \\
1928 & $14 \cdot 7$ early October & $8 \cdot 9$ early February \\
1929 & $14 \cdot 0($ ?) end of first week in October & $8 \cdot 4$ early March
\end{tabular}

The isopleth diagrams in Figures 5, 6, and 7 show the temperature changes which have taken place each year at Station $\mathrm{E}_{1}$. Black circles indicate the dates upon which series of observations were taken, and from which the isopleths are drawn.

The general distribution of temperature in the western part of the English Channel during the winter of 1927-28 is shown on the charts in Figure 8. These are compiled from surface temperatures on the crossChannel steamship routes shown in Figure 1. They show the loss of heat during November to be most rapid in the less deep area to the eastward, which is a general phenomenon.

With regard to the fluctuations from year to year there is, I think, only one outstanding instance where the inflow of warmer water unmistakably and materially affected the cycle; in the autumn of 1921. During other years inflow of warmer or colder water undoubtedly took place from time to time (March, 1928), but the effect of such upon the temperature cannot be clearly distinguished from the effect of fluctuating meterological conditions-solar radiation, dryness of the atmosphere leading to increased evaporation, and clear sky at night leading to increased radiation of heat into space.

In Figure 9 the observed salinities of the water at various depths at $\mathrm{E}_{1}$ are given for the latter part of 1921, and below the integral temperature of the whole column of water from surface to bottom. An accretion of heat took place between September 15th and October 18th, a time when the water is normally losing heat. A similar curve for the following year is given below. Presumably as a result of this inflow of more saline and warmer water, a singularly warm and late autumn was experienced (Harvey, 1925). 


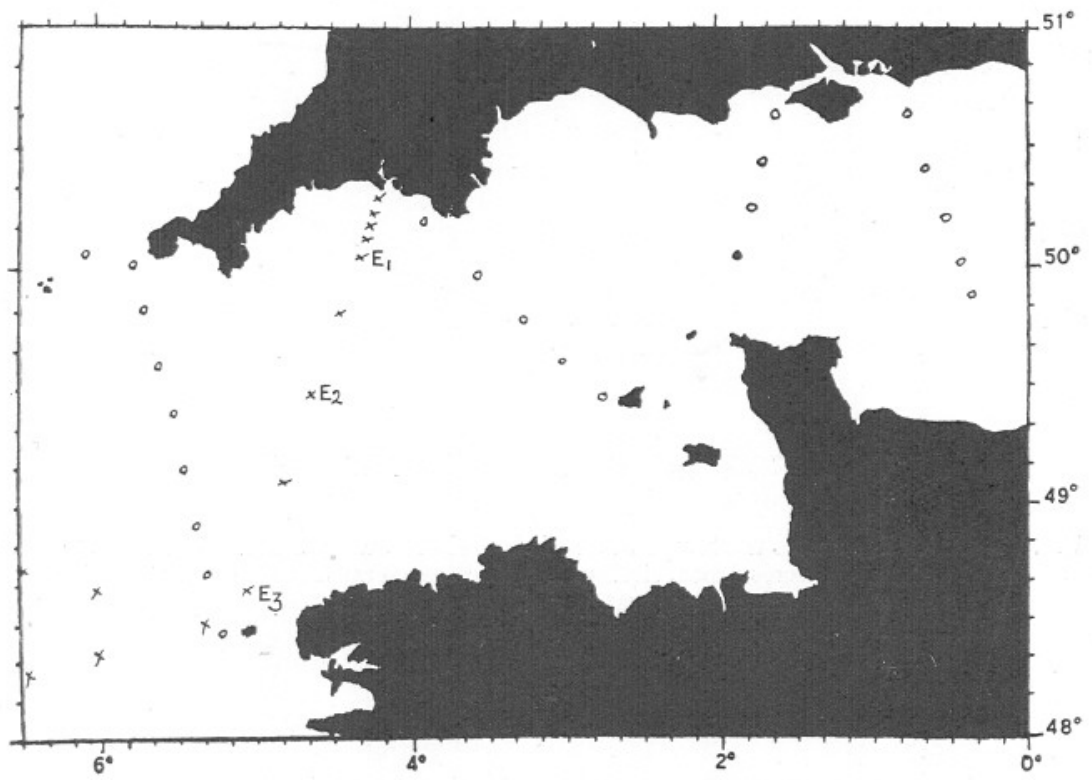

FIG. 1.-Circles indicate positions at which surface samples are taken at regular (fortnightly) intervals. Crosses indicate positions at which research vessels work stations or take surface samples.

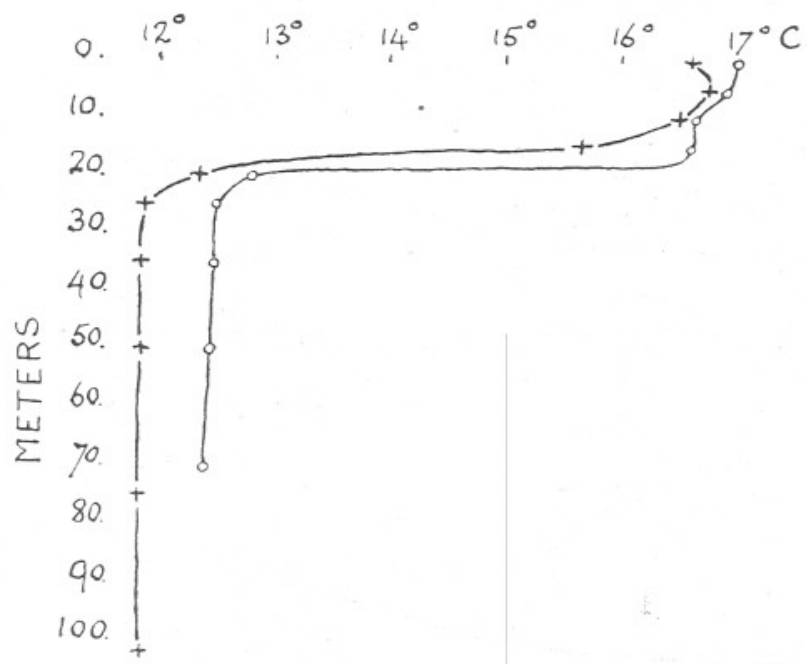

Fig. 2.-Circles indicate the temperature observed at Station $\mathrm{E}_{1}$ on August 2nd, 1927 ; crosses indicate the temperature at Station $\mathrm{E}_{3}$ on August 3rd, 1927. 

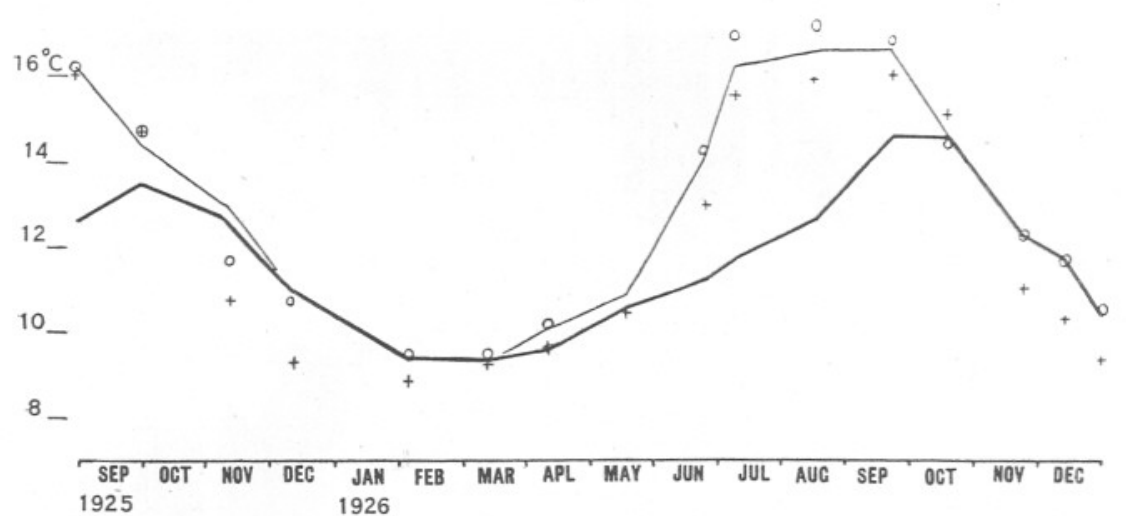

Fig. 3.-Thick line shows the temperature of the bottom water, thin line the temperature of the water at 5 metres depth, circles the surface temperatures observed at Station $\mathrm{E}_{1}$, crosses show the surface temperatures observed off the western end of Plymouth Breakwater.
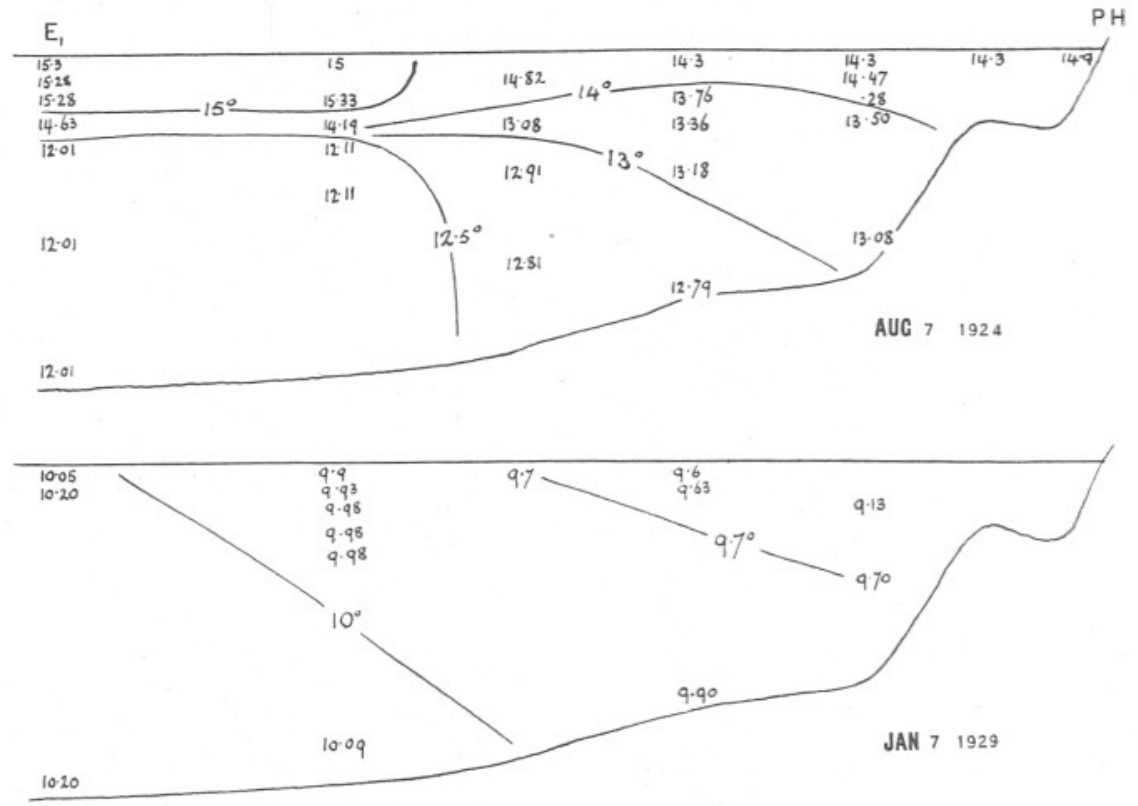

FIG. 4.-Sections between'Station $E_{1}$ and Plymouth showing the distribution of temperature with depth. 

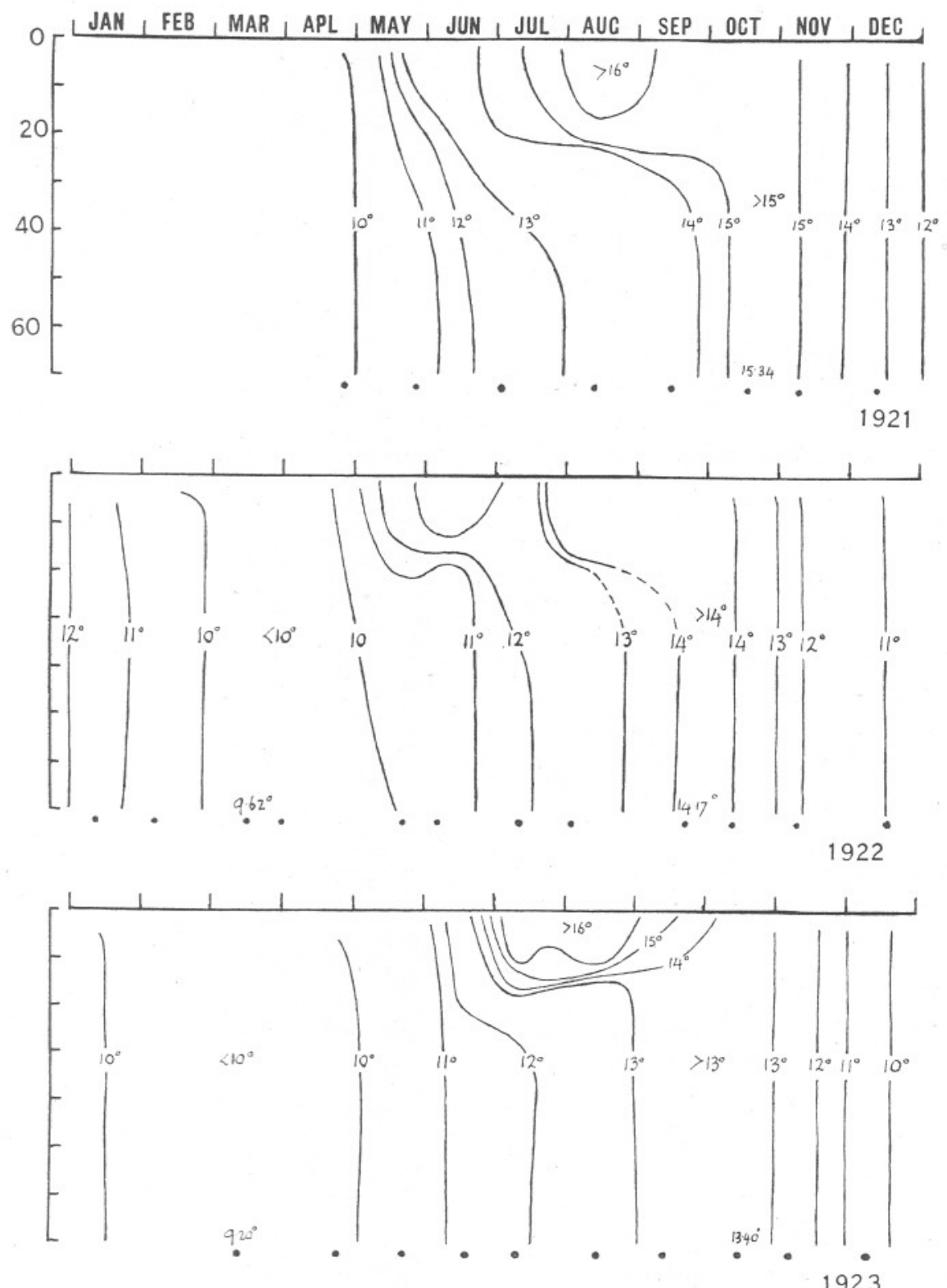

FIG. 5.-Isopleth diagrams showing the distribution of temperature with depth from April, 1921, to December, 1923, at Station $\mathrm{E}_{1}$. 

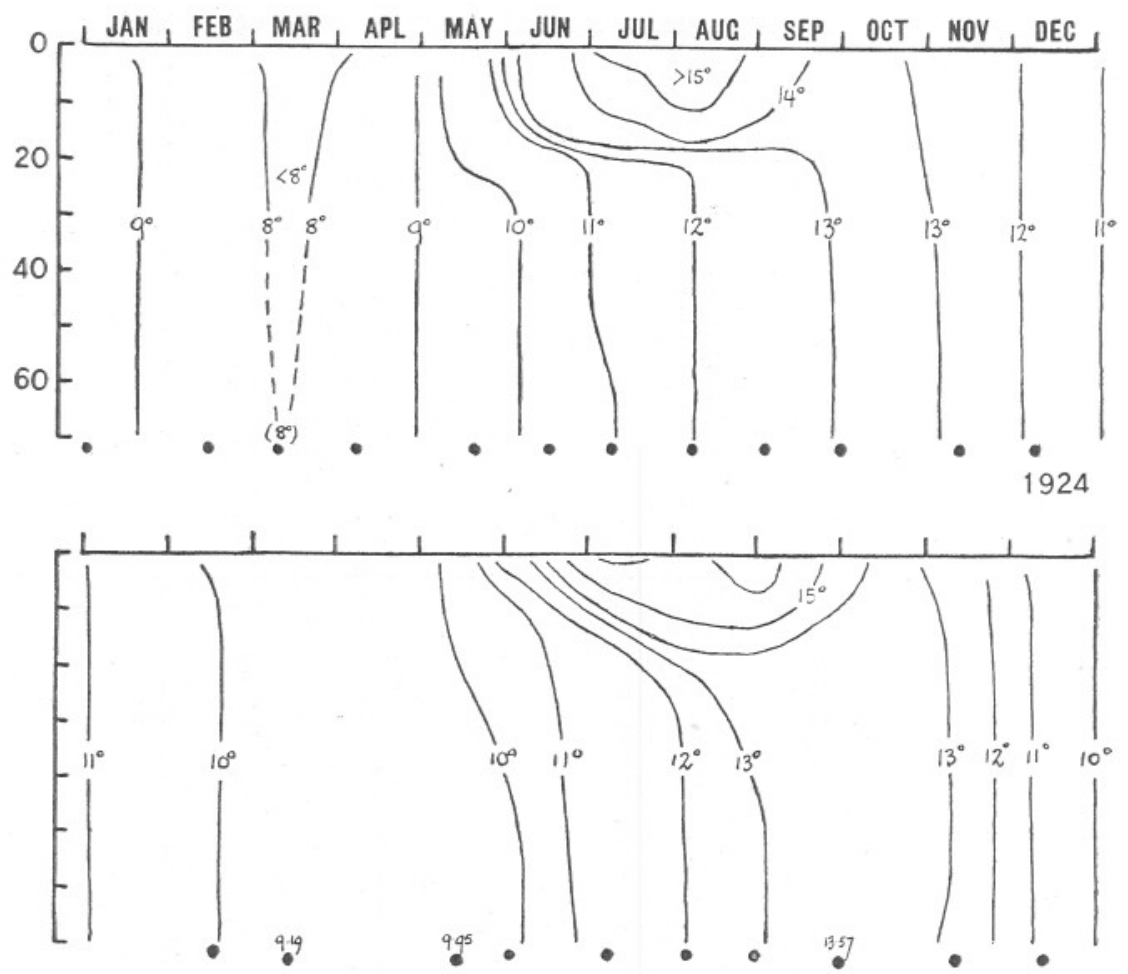

1925

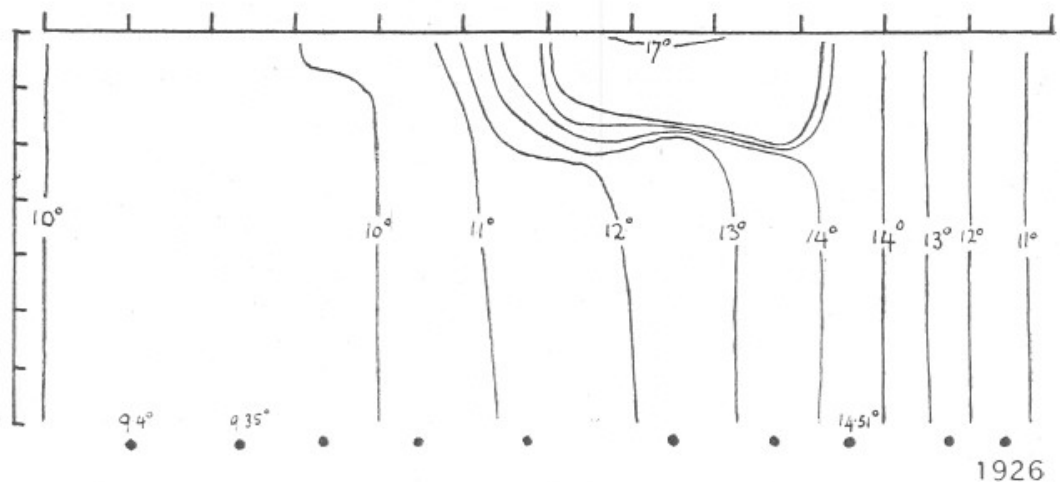

FIG. 6.-Isopleths, showing distribution of temperature with depth at Station $\mathrm{E}_{1}$ during 1924, 1925, and 1926. 

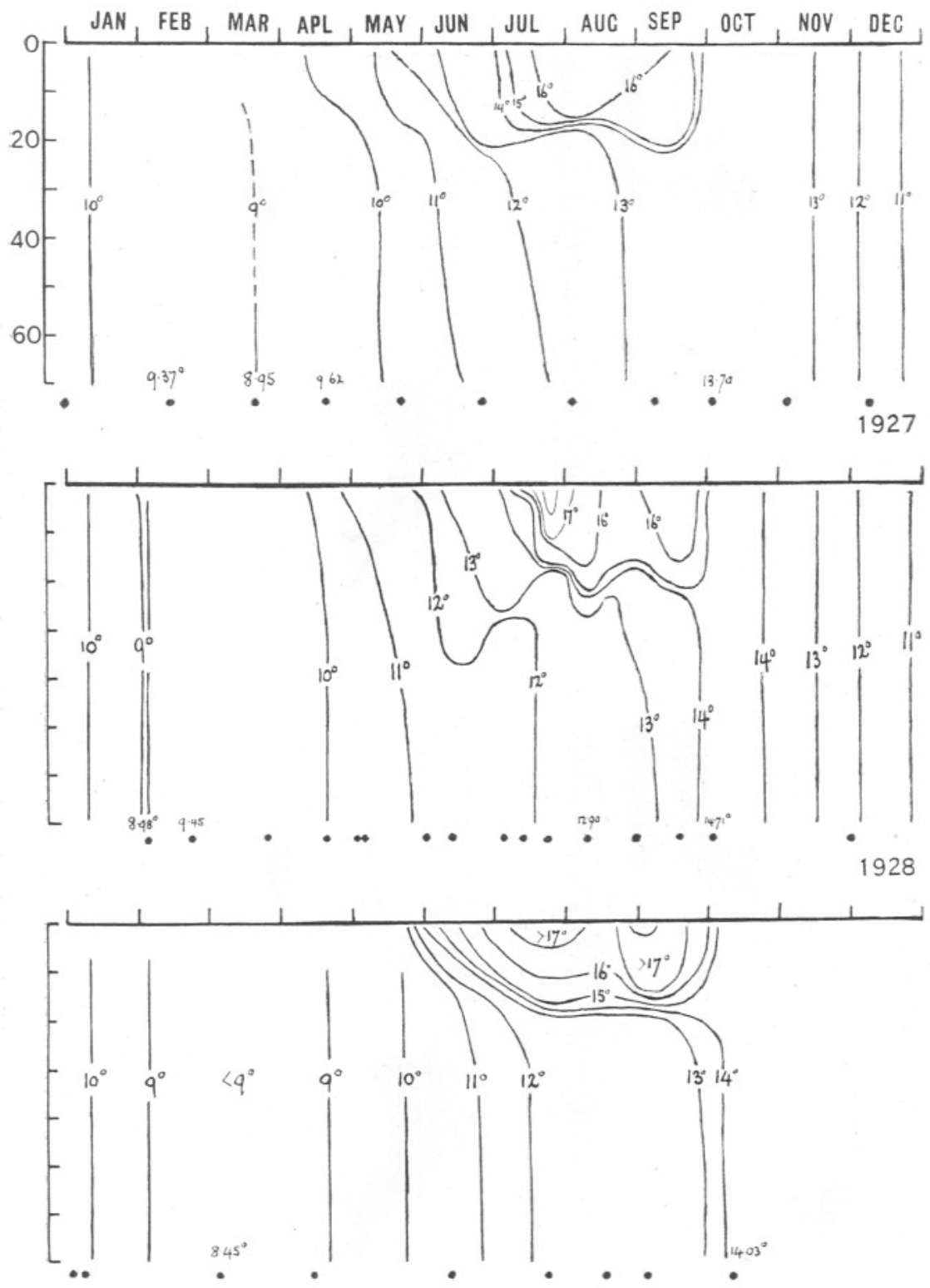

Fra. 7.-Isopleths showing the distribution of temperature with depth from January, 1927, to Oetober, 1929. 

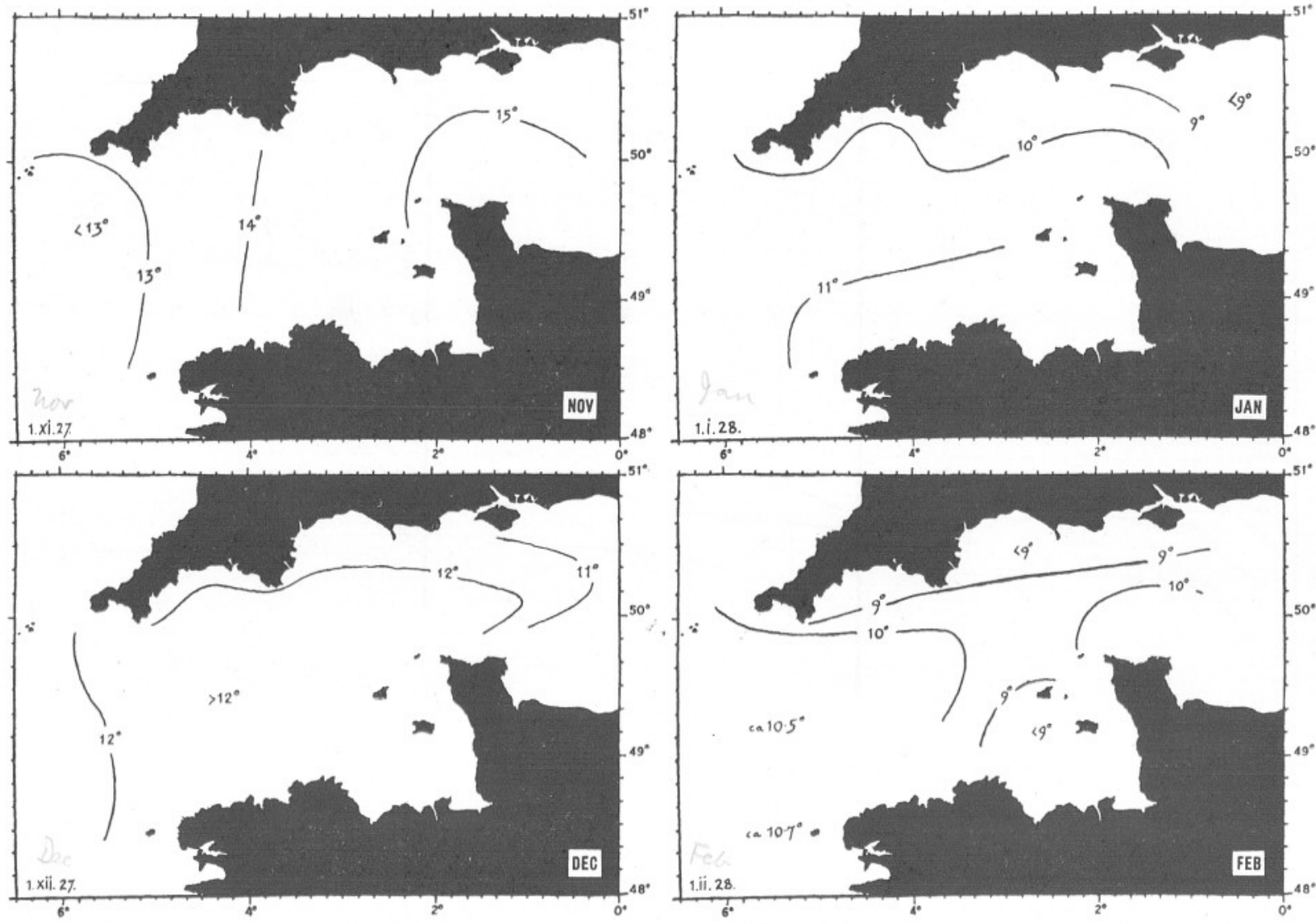

Fig. 8.-Distribution of temperature during the winter of 1927-1928. 


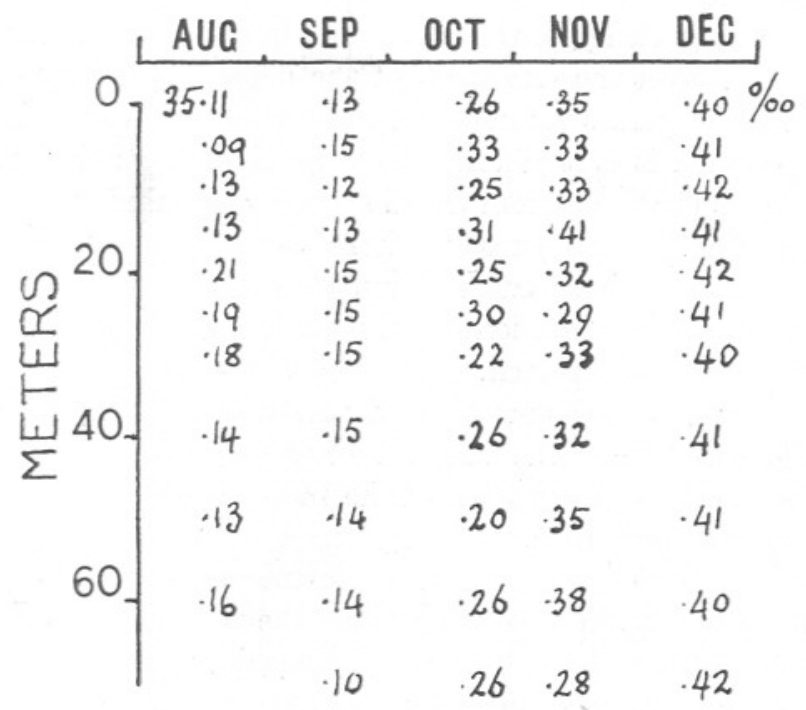

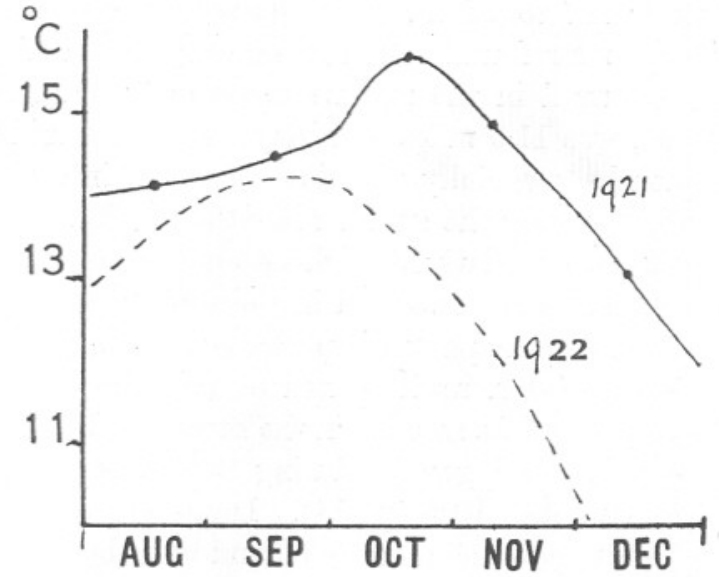

FIG. 9.-Upper diagram shows the salinity of the water observed at Station $\mathrm{E}_{1}$ from August to December, 1921 ; lower diagram shows the integral mean temperature of the column of water from surface to bottom. 


\section{PART II. THE DISTRIBUTION OF SALINITY AND CIRCULATION OF THE WATER.}

Our present knowledge of the circulation in the English Channel rests upon inference, with the exception of the definite proof by Carruthers (1928) that water passes through from the Atlantic into the North Sea. In this connection it is significant that the general conclusions arrived at by Matthews (1905-14) from the distribution of salinity and temperature and by Gehrke (1907) rest unaltered by subsequent observations. It does appear, however, that the circulation of the water masses, and in consequence the distribution of salinity, is more irregular and intermittent than hitherto expected.

The following brief account aims at presenting a generalised picture of the western part of the English Channel, before discussing the occurrences which are suggested by the more intense surface sampling carried out since June, 1925.

A continuous series of current measurements made by Carruthers (1928) at the Varne Light vessel shows that the residual current normally passing from the English Channel into the North Sea is occasionally held up, or even reversed for a period, by easterly and north-easterly winds, and is at other times greatly augmented by strong south-westerly winds. The mean residual movement past the Varne Light vessel at a depth of 11 metres was found to be $2 \cdot 7$ miles daily, into the North Sea, the maximum value so far found was 16.8 miles. The maximum residual current which occurred in the reverse direction, from the North Sea into the Channel, was 11.9 miles in a day. It was found that during the autumn months especially the flow of water into the North Sea was greatest, while during the summer months the flow was least.

Water of variable but relatively high salinity enters the mouth of the English Channel and passes eastward in the form of a tongue (Fig. 10). This tongue of water on its passage up Channel becomes more and more diluted with coastal water, itself diluted by land drainage. In spite of greater rainfall in winter, its salinity in the Straits of Dover at the Varne Light vessel is in general greater during the winter than during the summer months (Lumby, 1925, p. 14). Doubtless this is due to the increased speed of its passage up Channel and into the North Sea during the autumn and winter. A peculiar phenomenon in connection with the salinity of this tongue of water as it extends eastward has been pointed out by Lumby (1925, p. 4), who noted that during the years 1921 and 1922 the average salinity of the water increased as it passed on to the relatively shallow soundings between Newhaven and Dieppe, being higher there than where the tongue was deeper and nearer the Atlantic, on the line Southampton-St. Malo. He considered that more 
saline water had crept up Channel as a subsurface current to mix with water above and so appear on reaching shallow soundings, where wave motion and tidal streaming over the bottom bring about effective vertical
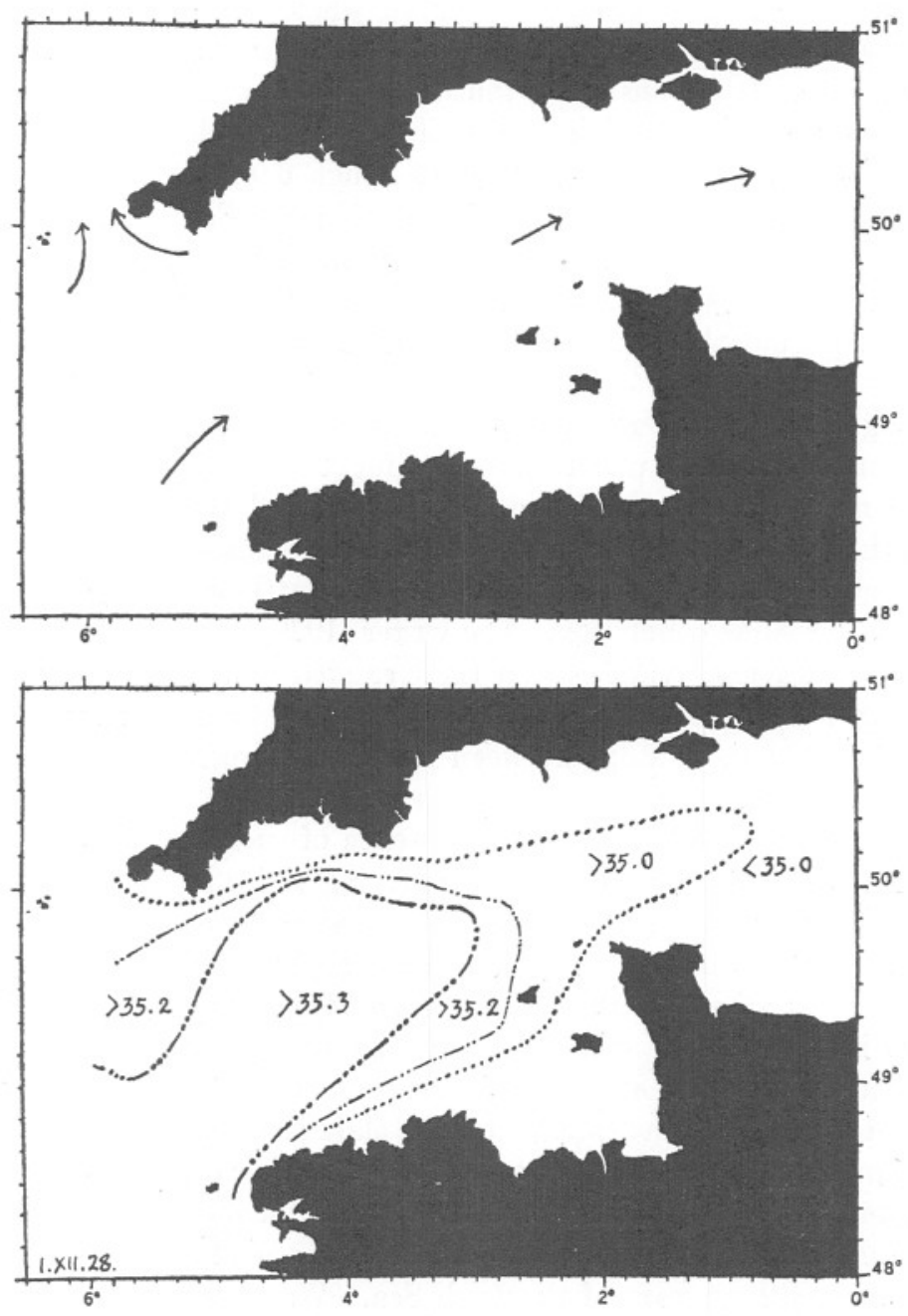

FIG. 10.-Upper diagram shows the general current system. Lower diagram shows a type of distribution of salinity expected to arise from such a system of currents.

mixing. These two years were remarkable for the inflow of highly saline water from the Atlantic. A description of the movements of bottom trailing and surface drift bottles during 1924 is given by Carruthers (1927) 
who also discusses the question of cyclonic swirls set up by the penetrating tongue of water.

The shape or form of this tongue of water is very variable (Figs. 13-16). In winter the salinity is generally much the same from top to bottom; in summer the number of cases observed where more saline water has penetrated under a layer of less saline water to any great distance are not numerous. It is considered that maps showing the surface salinity in this area are usually a fair rough picture of the salinity of the whole water mass. The picture is certainly a rough one, on account of this, of the limited intensity of sampling, and of errors likely to arise during or after rainy weather or heavy evaporation. Further, it is clear that the isohalines do not actually follow the smooth lines usually indicated in such maps, but that numerous offshoots, lacunæ and isolated patches exist.

Passing next to the circulation at the mouth of the Channel, Gehrke (1907) considered that under the centrifugal force due to the earth's rotation more water entered the English Channel than passed on into the North Sea, the surplus running out past the Lizard and Land's End. From the distribution of salinity and density, Matthews and later Lumby arrived at the same conclusion. The writer (1929) from hydrodynamical considerations found evidence that there existed a north-going difference in velocity between the surface water and the layer at 60-metres depth amounting to $1 \frac{1}{2}$ miles a day between Land's End and the Scillies at the end of Juné, 1924.

There can be little doubt of the existence of such a residual current, superimposed on the tidal streaming, carrying water northward into the mouth of the Bristol Channel - variable in velocity and perhaps intermittent. Such a current system as suggested would be expected to give rise to a salinity distribution of the type shown in Figure 10. Changes in the current system would lead to changes in the salinity distribution; hence the value of mapping the latter at short intervals of time in order to gauge the changes taking place in the general circulation. Such changes frequently appear to be swift and of short duration.

With regard to this general current system at the mouth of the English Channel, Matthews (1911 and 1914) found evidence of a cyclonic circulation in the southern part of the Irish Sea. Water moving northwards past Land's End and curling towards the south-east coast of Ireland moved southwards and westward to rejoin the north-going stream past Land's End. There was evidence that a similar movement of the upper layers over the stratum at 60 metres existed at the end of June, 1924 (Harvey, 1929). Matthews found evidence that the southern boundary of this cyclonic system lay further southward during the winter months. The more saline Atlantic water entering the Channel then lay closer to 
Ushant, the northern part of the mouth of the Channel being blocked by the less saline water of this cyclonic system.

The water, lying at the mouth of the English Channel and forming the base of the tongue which extends eastward, is of very variable salinity. Thus in February, 1903, water of $35.5 \%$ lay north of Ushant and in July of 1928 the whole mouth of the Channel was filled with water of under $35.0^{\circ} \%$.

As the Atlantic Stream creeps gradually northward along the edge of the continental shelf it undergoes gradual dilution: when the stream is least torpid, water of high salinity may be expected to swing from the ocean into the mouth of the English Channel under the influence of the earth's rotation. When, in addition, wind favours its passage onward and through the Straits of Dover the highest salinity at the entrance of the Channel might be expected.

These surges of the Atlantic Stream are very variable as judged by the change in latitude of the isohalines in the open ocean and the salinity of the water which penetrates, perhaps welling up, into the relatively shallow soundings at the mouth of the English Channel and in the Irish Sea.

The most notable effects recorded are those in 1903 when high salinity water persisted for over two years and again in 1921. In the early summers of 1923 and 1928 an unusual condition was observed. After heavy rains in the Loire watershed (Atkins, 1929) the English Channel filled with water of abnormally low salinity, much of which apparently came from the west coast of France, moving northward and entering the Channel past Ushant. By July, 1928, the entire Channel was filled with water having a salinity of less than $35.0 \%$ (Figs. 15 and 16).

\section{The Surface Salinity Diagrams.}

The routes along which samples have been taken, about twice monthly, are shown in Figure 1, in which circles indicate the usual positions of sampling. The data obtained since June, 1925, when the line PlymouthGuernsey was commenced, have been plotted in the manner shown in Figure 11. It is usually simple to draw lines marking salinities of $35 \cdot 0$, $35 \cdot 2,35 \cdot 3$, etc., and so obtain moderately true isopleths indicating the change in salinity with time and with position along the particular route. Not infrequently high salinities are found at one or two positions at a particular date, while no such high values were obtained either a fortnight previously or a fortnight later. This may mean that a narrow tongue has penetrated to the position shown and breaks up to disappear by mixing with the surrounding water mass during the ensuing fortnight, or alternatively that an outlying patch happened to be passing across the 
route. In some instances further evidence can be obtained from stations in the neighbourhood which have been sampled at various depths within a few days of the occurrence by a research vessel.

From these isopleth diagrams 43 charts have been prepared showing the distribution of surface salinity at the beginning of each month. Lines are drawn connecting up the positions at which salinities of $35 \cdot 0,35 \cdot 2$, $35 \cdot 3$, etc., occur on each route, wherever possible due regard being paid to data obtained shortly before or after at various depths by the research vessels.

There can be little doubt that these boundary lines are in fact very

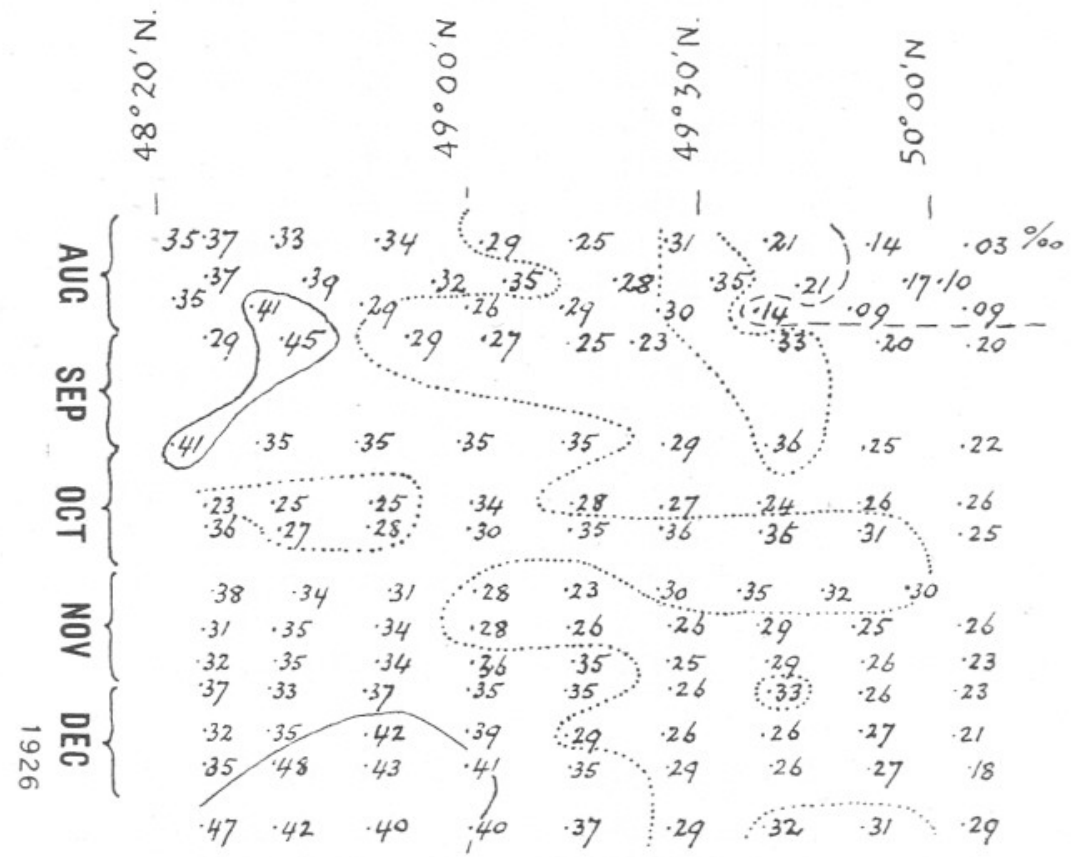

FIG. 11.-Portion of surface salinity isopleth diagram across the mouth of the English Channel (line Longships L.V. to Ushant).

irregular, with indentations, lacunæ, and outlying patches, but the fair lines drawn in such diagrams are the only means of indicating the general distribution without having data from impracticably intense sampling. Further, on some occasions less saline water lies over more highly saline or vice versa, the isohalines lying obliquely, not vertically; an outlying patch may be near the surface and not extend to the bottom, as was found by Matthews on occasions.

However, on taking the available evidence as a whole, a conclusion does seem justifiable that such charts give a tolerable rough picture of the 
distribution of the water masses on most occasions. Any inferences regarding the movements of the water masses, as deduced from the changes they bring about in the distribution of surface salinity, rest upon the validity of the above conclusion. In the area under discussion there have been only a limited number of stations worked from top to bottom within two or three days of each other since June, 1925. If we consider a wide area, however, the distribution in February, 1927, is interesting because the French, Irish and our own vessels worked lines of stations all between the 15th and 18th. In Figure 12 the surface salinities along the steamship routes marked with circles are filled in from isopleths, and the actual observed salinities along the routes followed by the research vessels are for the most part shown in the sections. In the deep water south of Ireland the isohalines are not usually vertical-the presence of layers of more saline water sandwiched between less saline water above and below was particularly noticeable during the summer of 1929 . Towards the eastern end of the English Channel and in the shallower part of the North Sea the salinity is usually the same from top to bottom. In such areas, therefore, changes in the distribution of surface salinity are more nearly representative of the movements of the water masses.

Turning next to the 43 distribution diagrams from June, 1925, to December, 1928, we find during this time an irregular inflow of high salinity water from the Atlantic into the mouth of the Channel and its disappearance. The most marked and lasting instances are shown in Figures 13, 14 and 16 respectively, while in Figure 15 is shown an incursion of low salinity water rounding Ushant and passing into the English Channel.

From June, 1925, to the end of 1926 water having a salinity of over $35.3 \%$ usually lay to the westward of the line Lizard-Ushant. However, during the month of January, 1926, there was a marked incursion of this water into the Channel extending to about $2^{\circ} 40^{\prime} \mathrm{W}$. long. (Fig. 13). By the beginning of March it appeared to have mostly moved northwestward and on April lst was only found in the neighbourhood of the Scillies. During the next three months there was a fall in salinity in the mouth of the Channel and at the beginning of July the mouth was filled with water having a salinity less than $35 \cdot 2 \%$. It is not clear how this fall in salinity arose. There is no reason to suppose that on the whole low salinity water from the North Sea moved into the Channel during the period February to June, nor is there any decided indication of low salinity inshore water from the west coast of France entering the English Channel through the Le Four Channel or close to Ushant.

If we consider the distribution of the water masses having a salinity greater than $35.3 \%$ on February 1st, 1926 (Fig. 13), it is difficult to conceive how this great mass of water can have become diluted by 


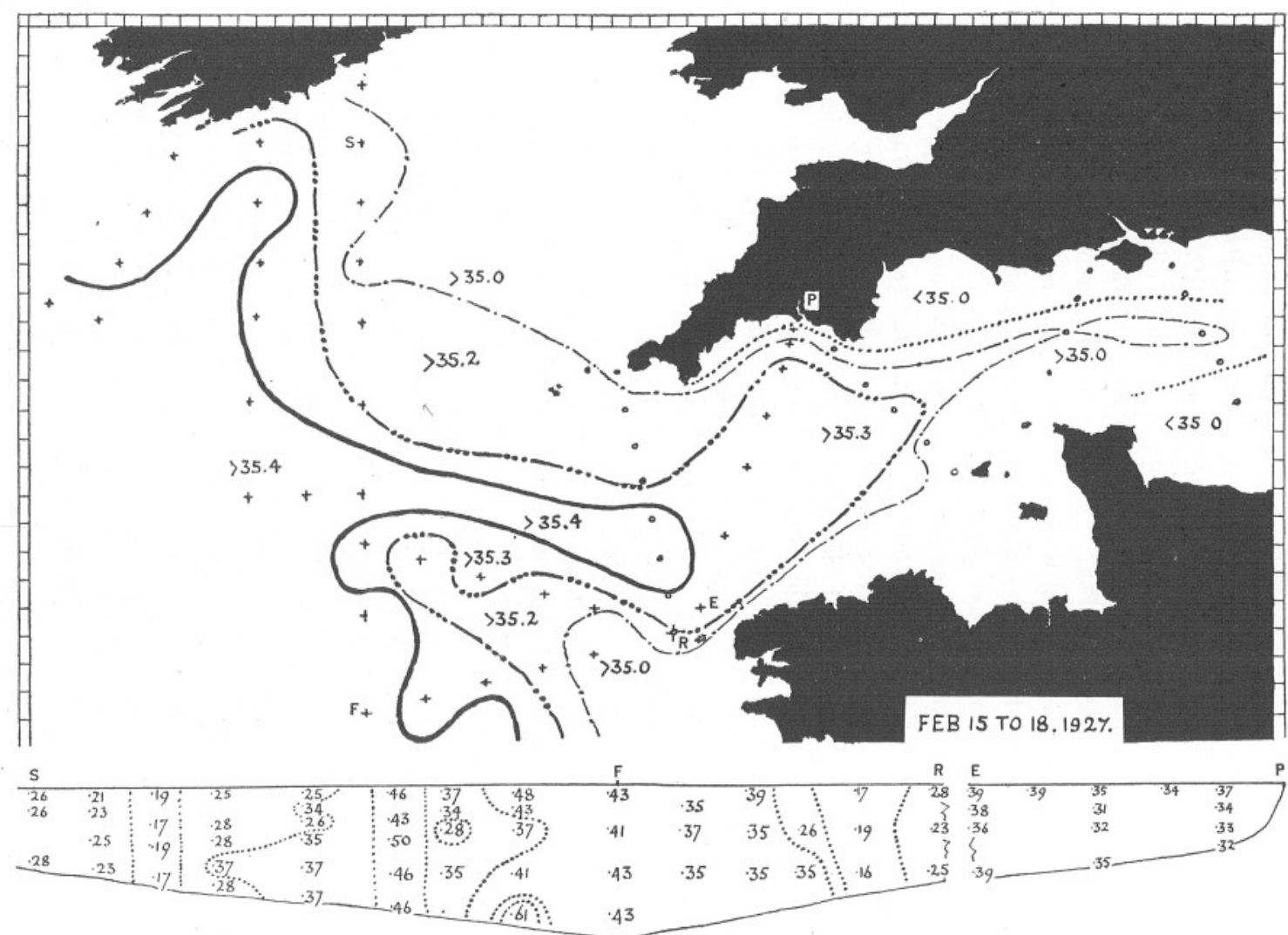

Fia. 12.-Chart showing the distribution of surface salinity, February 15th to February 18th, 1927. Sections P to E, $\mathrm{R}$ to $\mathrm{F}, \mathrm{F}$ to $\mathrm{S}$, showing the distribution of salinity with depth between the same dates. 
infiltration and mixing along the edges within two months to give rise to the condition shown for April 1st. It seems much more probable that most of it had slowly swirled away north-westward, retaining its characteristic salinity, and had been largely replaced. The same argument applies even more clearly to the changes portrayed during March, April, May, and June, 1927, in Figure 14. Even in the case of a small patch or outlier of water, having a salinity greater than that of the surrounding water mass, and a surface area of no more than one or two hundred square miles, it is difficult to conceive that it would mix horizontally with the surrounding less saline water at all rapidly. Rather it might be expected that much of it would retain its characteristic higher salinity for several weeks or more.

From July, 1926, to December no samples were obtained on the Plymouth-Guernsey route, and the other data do not show any remarkable changes.

From December, 1926, to March, 1927, a decided inflow of Atlantic water into the mouth of the Channel is shown in Figure 14. The inflow indicated as taking place during December represents a volume of water of over 120 cubic miles. Current measurements at the Varne Light vessel indicate that during this month of December about 18 cubic miles of water per day passed from the North Sea into the English Channel-a reversal of the usual direction of the residual drift. Hence, in order to make way for the incoming Atlantic water, it is not improbable that over 120 cubic miles of water passed out of the Channel round the Lizard and Land's End. Assuming that this west-going stream extends for about 12 miles off shore, its velocity residual to the to and fro tidal streaming would average about 9 miles per day, perhaps rather more, during this particular month. Tidal stream observations off the Lizard in calm weather, probably only in summer, indicate a residual component in a westerly direction. "Off the Lizard the streams are of nearly equal duration, the west-going stream running . . . at a maximum rate of 3 knots near the rocks; and the east-going stream . . . at a maximum rate of 2 knots at springs" (The Tides and Tidal Streams of the British Isles, Tizard, p. 43,1909$)$. During March, 1927 , the $35 \cdot 3 \%$ salinity water penetrated far into the Channel in the form of a narrow tongue (Fig. 14); some 35 cubic miles of water passed during the month into the North Sea helping to draw this tongue westward. During April, May, and June this formation broke up and there is indicated a gradual retreat northwestward of the higher salinity water.

From July, 1927, to March, 1928, there were no considerable intrusions of high salinity water.

During March and April, 1928, the mouth of the Channel filled up with low salinity water (Fig. 15), unusually transparent and rather warmer 
than usual for the time of year. It is suggested (Atkins, 1929) that this water came in part northward from the west coast of France, rounding Ushant into the English Channel, and in part from drainage from the Seine watershed. In the Loire and Seine basins the rainfall during February was approximately $75 \%$ above normal, and 50 to $60 \%$ above normal for the three months January, February and March. This low salinity water possibly overlay water of higher salinity in the neighbourhood of Ushant, at all events such a condition was found later on May 8th (Fig. 15, section).

Such a condition was only observed once before since 1921, when an upper layer of water having a salinity less than $35.0 \%$ was found extending some 60 miles north of Ushant in April, 1923. During this year also the rainfall in the Loire and Seine basins was exceptionally high, approximately $100 \%$ above normal for the month of February.

The next change of considerable extent is the inflow of higher salinity water commencing in July, 1928, and culminating on or after December, 1928 (Fig. 16).

The proofs of this paper have been read by Lieut.-Comdr. J. R. Lumby, to whom I am further indebted for several suggestions. 

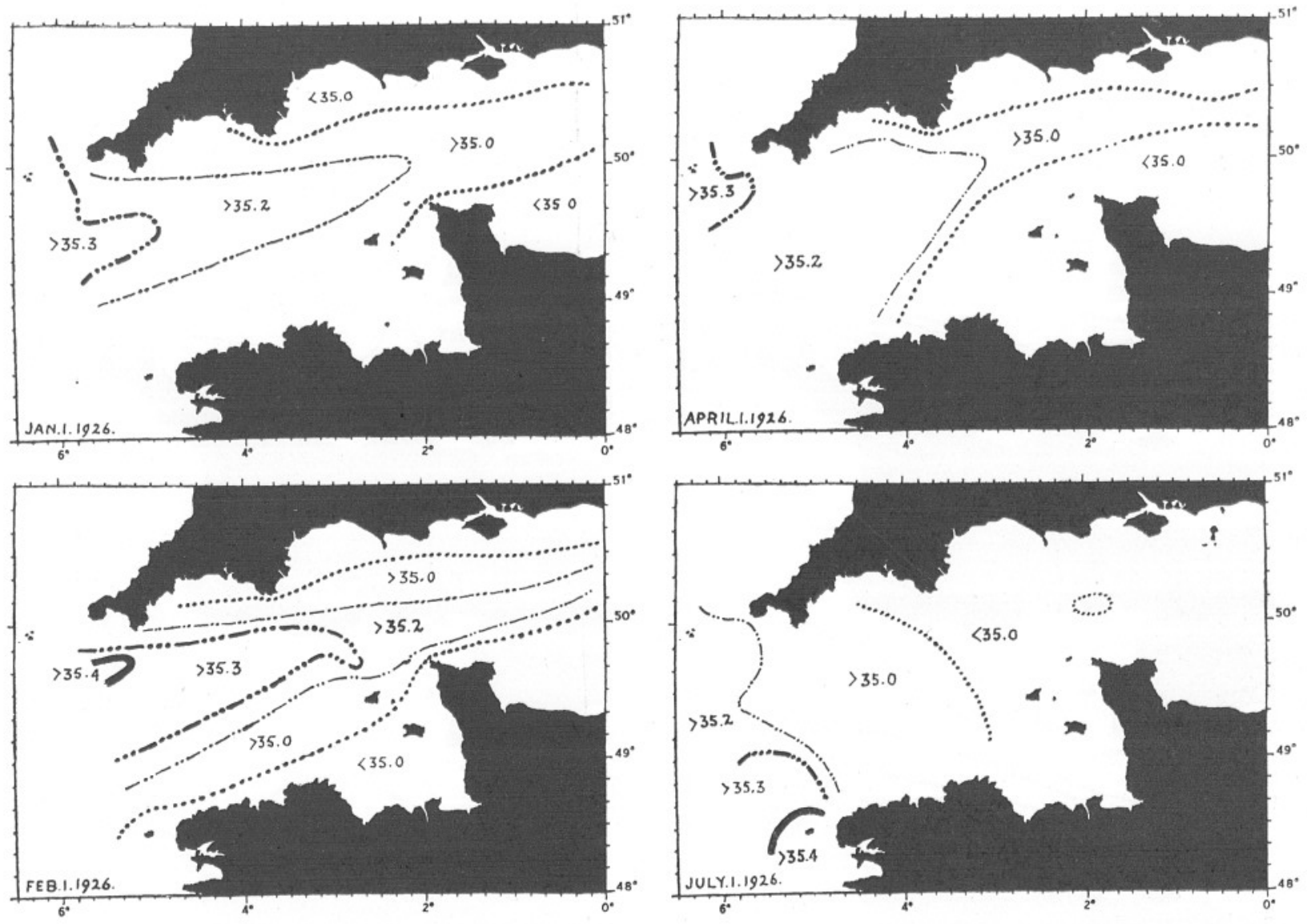

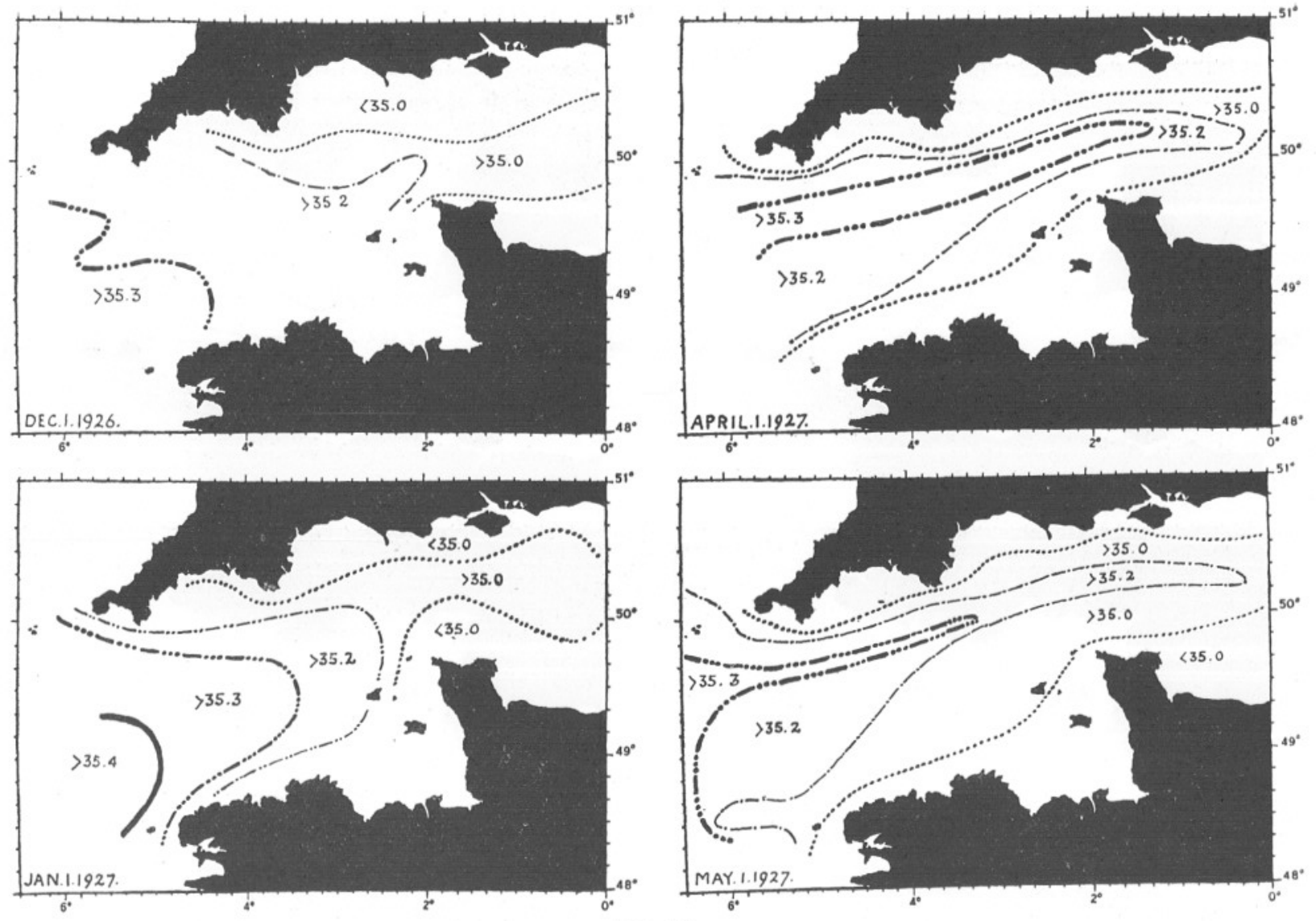

平 

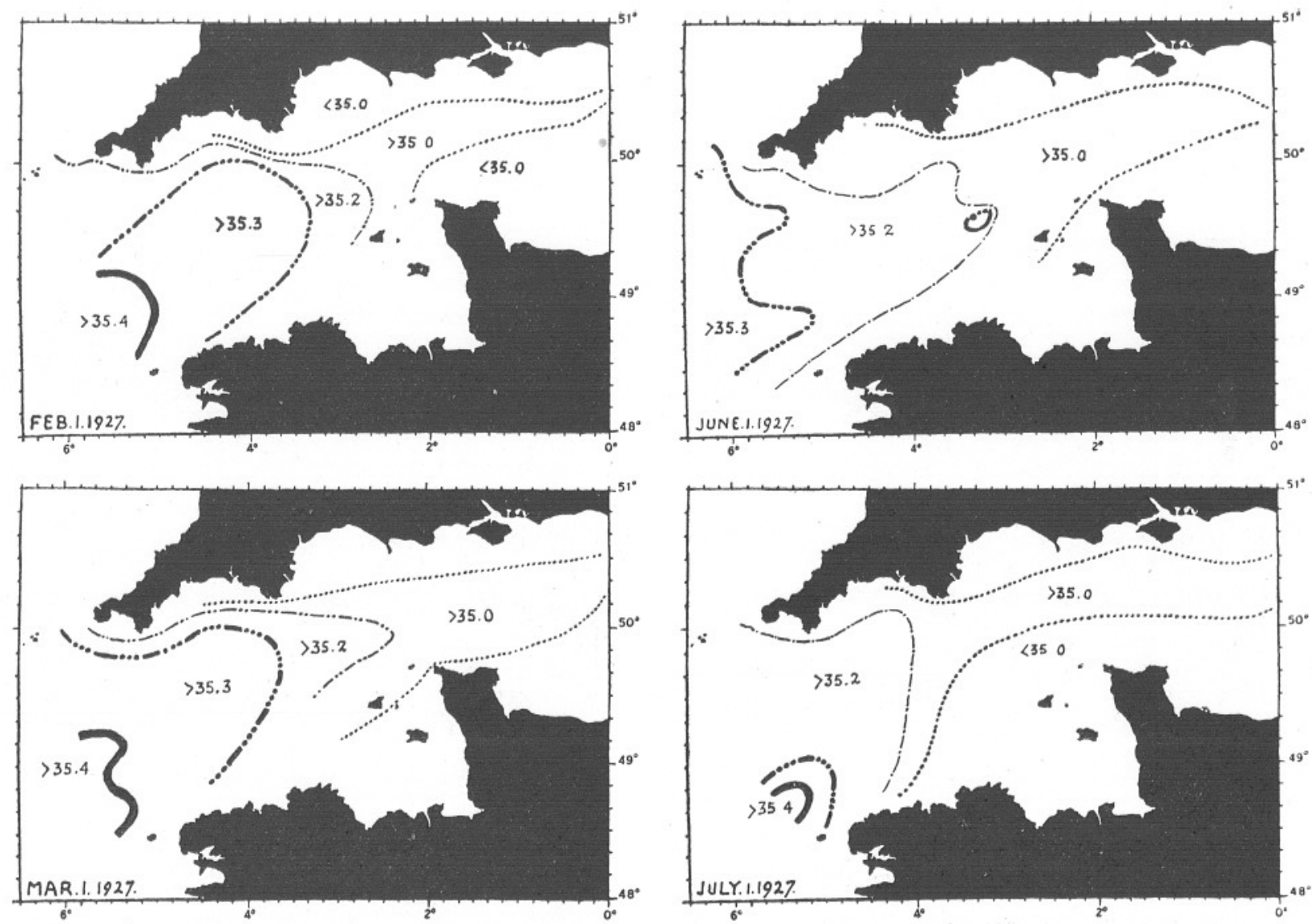

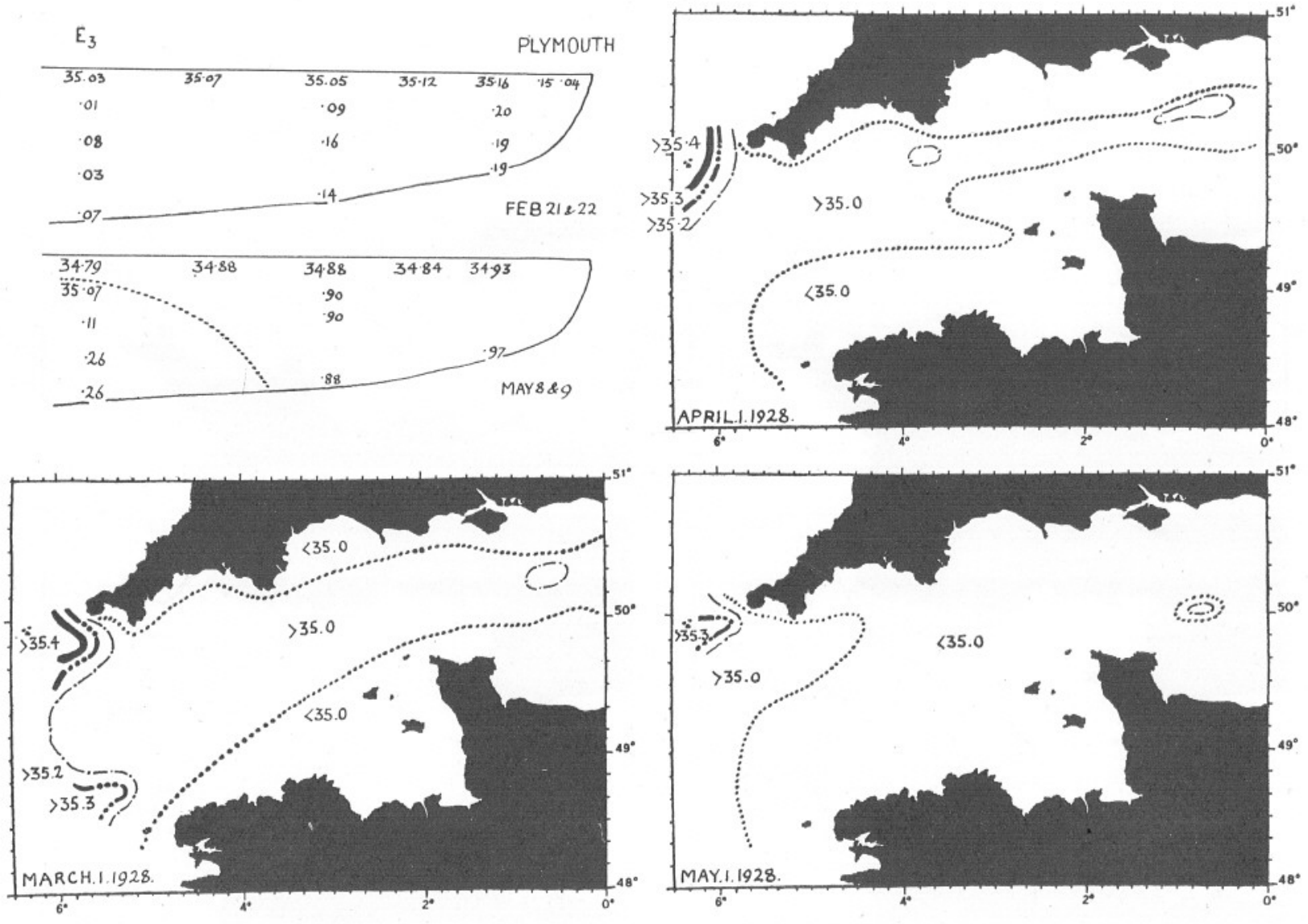

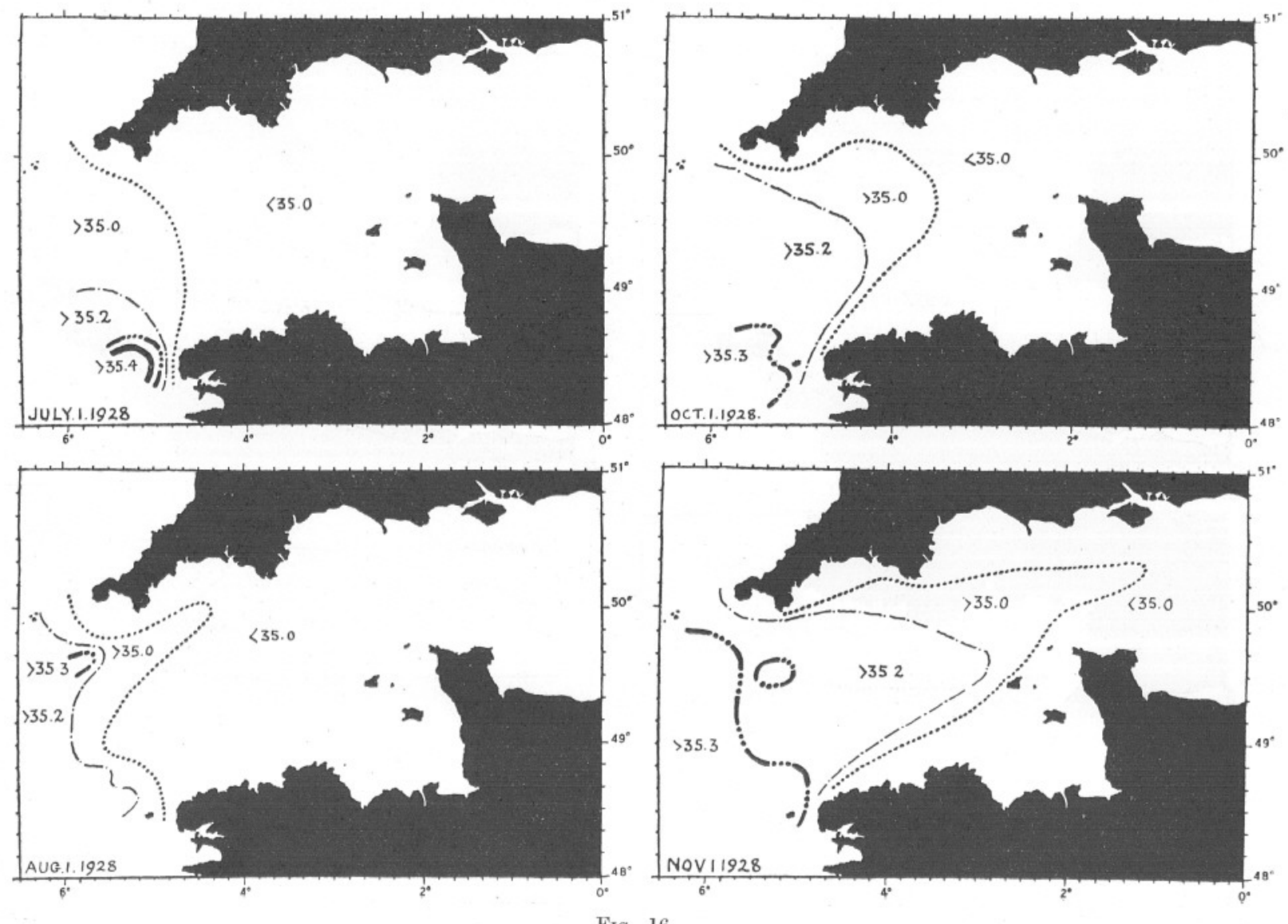

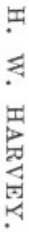




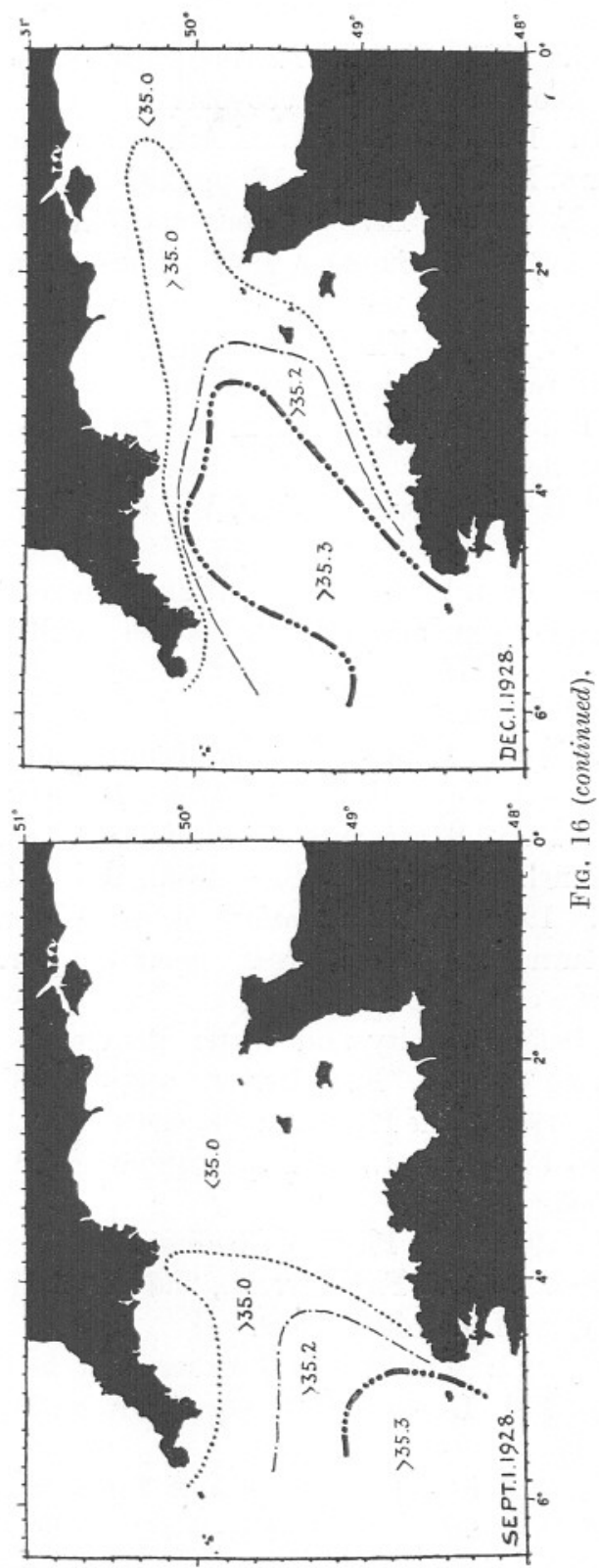




\section{REFERENCES.}

Atkins, W. R. G. 1925. On the Thermal Stratification of Sea-water. Journ. Mar. Biol. Assn., 13, pp. 693-699.

Atrins, W. R. G. 1929. See Poole and Atkins, Photoelectric Measurements. Journ. Mar. Biol. Assn., 16, pp. 297-356.

Carruthers, J. N. 1927. Investigations upon the Water Movements of the English Channel, Summer, 1924. Journ. Mar. Biol. Assn., 14, pp. 685-721.

Carruthers, J. N. 1928. The Flow of Water through the Straits of Dover. Fish. Invest., Series 2, Vol. 9, No. 1.

Danois, E. LE. Rapport Atlantique, 1921 to 1928. Cons. perm. Internat. pour l'explor. de la Mer.

Fond, E. 1929. Herring Investigations, V. Jour. Mar. Biol. Assn., 16, pp. 1-24.

Genrke, J. 1907. Mean Velocity of the Atlantic Currents running North of Scotland and through the English Channel. Publ. de Circ., No. 40.

Harvey, H. W. 1924.S Hydrography of the English Channel. Rapport Atlantique, 1924, pp. 60-89.

Harvey, H. W. 1925. Evaporation and Temperature Changes in the English Channel. Journ. Mar. Biol. Assn., 13, pp. 678-692.

Harvey, H. W. 1925. Water Movement and Sea Temperature in the English Channel. Journ. Mar. Biol. Assn., 13, pp. 659-664.

Harvey, H. W. 1929. Hydrodynamics of the Waters south-east of Ireland. Journ, de Cons. Internat., pour l'explor. de la Mer, 4, pp. 80-92.

Lumby, J. R. 1925. Salinity and Water Movements in the English Channel during 1920-23. Fish. Invest., Series 2, Vol. 7, No. 7.

Matthews, D. J. 1905. The Physical Conditions in the English Channel, 1903. N. Sea Fish. Invest., 1st Report (Southern Area), 1902-1903, Cd. 2670, 1905 .

Matthews, D. J. 1909. The Physical Conditions in the English Channel, 1904 and 1905. N. Sea Fish. Invest., 2nd Report (Southern Area), 1904-1905, Part II, Cd. 4641, 1909.

Matthews, D. J. 1911. "The Physical Conditions in the English Channel, 1906. N. Sea Fish. Invest., 3rd Report (Southern Area), 1906-1908, Cd. 5546, 1911.

Matthews, D. J. 1914. The Salinity and Temperature of the Irish Channel and the waters south of Ireland. Fisheries, Ireland, Sci. Invest., 1913, No. 4, 1914.

Orton, J. H. 1920. Sea Temperature, Breeding and Distribution in Marine Animals. Journ. Mar. Biol. Assn., 12, pp. 339-366. 